\title{
Cartographers, Conciliators and Catalysts: Understanding the Communicative Roles of Researchers
}

\author{
Nicholas Benequista and Joanna Wheeler*
}

Abstract $A$ review of case studies from a global, ten-year research project coordinated by the Institute of Development Studies suggests that previous efforts to understand the value of research for promoting social change has underappreciated the contribution of researchers as social actors. Researchers inhabit a complex web of relations, they hold many identities, and they act politically to bring about social change in ways large and small that go beyond what they write in journals or in policy briefs. Through interviews and selfreflection, we explored some of these ways - formal and informal, direct and indirect - that researchers communicate their knowledge. To capture some of the diversity, this article presents a typology of different 'roles' that researchers play as communicators. We hope this typology might help to clarify our understanding of research utilisation, and might also provide insight into how to approach research communication in more strategic and creative ways.

\section{Introduction}

In Dhaka, Bangladesh, a group of professional researchers organised a colourful two-day event (22-23 January 2010) with music, theatre and art. They called it the nagorik adhikar mela (Citizen's Rights Fair), making use of a festive tradition to give the stage to community-based organisations from around the country. Nearly 60 organisations participated, using performance to present their work to civil society representatives, community development practitioners, journalists and citizens.

In the preceding decade, the organisers had carried out a series of quantitative and qualitative investigations into civil society mobilisation, citizenship, accountability and other related themes. They published journal articles, book chapters and policy briefs and spoke at numerous events about their findings. At the mela, however, their research hardly featured, at least by name. Yet even as they stayed out of the spotlight, their knowledge and ideas were very present.

The story of the mela, one of several case studies described in this article, illustrates an important point about the relationship between research and social change. That relationship is the central preoccupation of a field of enquiry often referred to as research utilisation (Jones 2009; Nutley et al. 2002; Weiss 1977). This literature has traditionally focused its attention on the speeches and publications researchers produce on the traditional, linear ways that researchers have tried to persuade people to use their ideas. Whilst work on research utilisation has produced insights into the effective dissemination of research, the mela is an example of how this view has too often neglected an array of ways that researchers put their knowledge into use, through a range of communicative roles.

In this article we make a case for a much more varied view of the role of researchers in research communication by drawing from the examples of a ten-year research programme - the

Development Research Centre on Citizenship, Participation and Accountability (Citizenship DRC) $)^{1}$ - that routinely encouraged reflection amongst its researchers on their contributions to social change, and not just as researchers per se, but in all of their many capacities.

In this article, we propose four wider communicative roles that researchers can play. 
As discussed by Lewin (this IDS Bulletin), researchers often work in conjunction with others, who may be communication specialists, film-makers, activists, journalists, etc. So whilst we focus on the particular role that researchers play as communicators, these researchers commonly acted as part of a larger group with diverse expertise.

We have labelled these roles using metaphors that resonated with researchers in the Citizenship DRC. We argue that some researchers, due to their particular social positions and assumptions about research, may be predisposed to particular roles. However, as researchers experiment with new methodologies - and, indeed, with novel approaches to research communication - they undergo a personal transformation, including by adopting a wider range of roles. In other words, these roles describe the forms of communication that are possible given certain kinds of knowledge, but also characterise how researchers view themselves. This framework thus approaches research communication not simply as an issue requiring 'capacity-building', but potentially as a site of conflict, and of personal change.

The four roles we describe are:

- Engineers and cartographers

- Mediators and conciliators

- Critical friends and advocates

- Catalysts and leaders.

\section{The Citizenship DRC's approach to research communication}

The Citizenship DRC was a research consortium funded by the UK Department for International Development (DFID), amongst other donors. During this period (2001-10), over 60 researchers in 25 countries contributed to the consortium's body of work. The Citizenship DRC had multiple objectives: to generate new knowledge, disseminate this widely to decision-makers and practitioners, and to build the capacity of partner institutions to carry out high-quality research, communication and policy engagement. The Citizenship DRC decided to take a somewhat novel approach to influence, using research to create collaborative and participatory spaces for engagement for a diverse range of stakeholders at multiple levels (Wheeler 2007).
This article is based on three sources of data. Citizenship DRC researchers participating in the consortium reflected regularly on their research communication in terms of social change, documented in a series of confidential workshop transcripts. Researchers in seven countries (Angola, Bangladesh, Brazil, India, Mexico, Nigeria and South Africa) submitted written reports exploring the issues addressed here. Finally, the authors of this article also carried out semi-structured interviews with researchers about their work.

\section{Who shares what knowledge and how?}

By role we mean the function that researchers serve as communicators of knowledge. These roles are determined by three elements, which can often be at odds with one another. Indeed, the tensions between these three elements can threaten the success of research communication:

- The form of knowledge possessed by the researcher with respect to a particular context;

- The form of engagement of the researchers with stakeholders in a given context; and

- The positionality of the researcher.

This article will briefly discuss each of these elements before describing how they are constitutive of specific roles.

\section{Forms of knowledge}

Within the literature on participatory research, there is an important emphasis on the types of knowledge that research produces. Building on Habermas' critical theory (1984a,b), Peter Park has proposed three types of knowledge (2001) that we have incorporated into our framework.

- Instrumental: knowledge that explains causal relationships, structures and functional relationships through the analysis of data.

- Interactive: knowledge that derives from how people interact with one another, including emotions, sharing daily experiences, and exchanging actions with a particular context.

- Critical: knowledge or theory that emerges from a combination of reflection and action that makes possible normative deliberations.

The research utilisation literature has in the past made reference to different classifications of research, suggesting that certain kinds of methodologies have different pathways to 
influence (Reimers and McGinn 1997; Weiss 1991). Using a typology of knowledge, however, has one major advantage over these approaches because it opens up the possibility for recognising that a researcher's knowledge does not come from research alone, but from a variety of other experiences, including from the act of research communication itself. This moves us towards better understanding for how research communication can be an integral part of a process of enquiry, as the examples below illustrate.

\section{Forms of engagement}

The mechanisms by which research enters the public domain are well examined, and have been variously described in theoretical terms as 'research functions' (Weiss 1977), or as a 'taxonomy of interventions' (Walter et al. 2003).

While these frameworks have focused on public policy influence, researchers in the Citizenship DRC aimed for broader goals. If the research helped to raise awareness amongst members of a grassroots group, informed a social movement's strategy, or helped a group of street-level bureaucrats to change their approach, this constituted influence.

By form of engagement, we refer to how researchers (individual or groups), interact with the people they perceive to be stakeholders, including the researched, themselves. For the purposes of this article, we define the forms of engagement narrowly by whether they allow for one-way, two-way, or multi-way forms of communications. ${ }^{2}$ As such, we define three categories of engagement:

- Dissemination: One-way forms of communication; these are the traditional approaches to research communication including journal articles, books, policy briefs, presentations, and documentaries - that assume that the research will be put into use by the audience.

- Consultation: Two-way forms of communication in which researchers solicit feedback on findings, done individually or in small groups, or in larger public meetings or vis-à-vis digital (online) platforms.

- Dialogue: Two-way and multi-way forms of communication that are moderated in some way by the researcher. This might include a debate amongst stakeholders, or a process of facilitated learning that is part of participatory research.

\section{Positionality}

Positionality refers to the relative social positioning of researchers in relation to their institutions, cultural contexts, and personal and professional networks. The importance of selfreflexivity in relation to research (particularly in anthropological and action research traditions) is well documented (Reason and Bradbury 2008). In effect, the roles and framework put forward in this article emerged from the periodic workshops hosted by the Citizenship DRC in which researchers critically reflected on their own experiences in communicating through and about their research. This critical reflexivity is especially important in the field of international development, which has been fraught with unequal power relations, including between researchers and the researched (Cooke and Kothari 2001; Eyben 2009).

\section{The communicative roles of researchers}

Whilst previous efforts to understand research utilisation have pointed to the importance of a researcher's positionality (Court and Young 2003; Nutley et al. 2002), none have proposed a typology, with the exception perhaps of

Maxwell's four varieties of 'policy entrepreneur': storytellers, networkers, engineers and fixers (Maxwell 2003). Maxwell's categories, however, were never intended to function analytically and failed to encompass the different roles we found embodied by researchers affiliated with the Citizenship DRC.

These roles come with the usual caveats of ideal types. All researchers may enact a combination of these features, or may perform different roles at different times. It is worth also noting that we do not presume to have an exhaustive sample of researcher roles or forms of engagement represented in our research project. We hope that others could add to this typology.

This section describes each of the roles that emerged through the analysis of the research communication process in 16 cases from the Citizenship DRC. Though space does not allow for all the cases to be described here, each role will be illustrated with one in-depth example that best typifies it. 


\section{Engineers and cartographers}

Engineers and cartographers rely on instrumental knowledge. They are researchers who devise solutions to problems through the systematic collection and analysis of data. On the inside, these researchers are often in the enviable position of giving a solution to an already recognised problem, like an engineer called in to fix faulty machinery. The user wants the researcher's knowledge, and may have even commissioned it. On the outside, researchers in these roles are often producing tools that may not have a specific audience in mind, much like a cartographer creates maps that might be useful for anyone travelling in the area.

The research conducted in Brazil illustrates this role. The investigation in Vale do Ribeira, a valley on the country's Atlantic coast where rainforest has been preserved, looked at how citizen participation was involved in planning for sustainable development, and in particular a proposed dam. Through surveys and interviews, they sought to understand how social movements organised their participation in the forums, and the repercussions that this had on the way they perceived and modified their position with respect to the dam and sustainable development.

The knowledge produced by the project was largely instrumental in that it sought to explain causal relationships through the analysis of data. This was also reflected in comments by one of the researchers about their role.

Today in Brazil we have a number of different councils, conferences, etc., and it's a kind of system that makes it difficult to coordinate. So we wanted to understand the structure and [how to] make it work better.

In terms of accounting for political interests and power, the research is certainly critical in a fashion, but the research did not produce the kind of 'normative deliberation' associated with Park's notion of critical knowledge.

The researchers carried out several activities to communicate their research. They consulted with social movement leaders on their findings, disseminated their conclusions and recommendations to high-level officials, and produced a documentary film on the public hearings carried out on a plan to build a dam.
During the process of communicating the research, several issues arose that illustrate the potential tensions created when forms of knowledge, researcher positionalities and forms of engagement all point to slightly different roles for the researchers.

One example arose from the researchers' efforts to influence presidential advisers. They found the government officials listened intently to the results of the study, but that no concrete actions were taken.

In this instance, finding themselves as a cartographer, someone who tries to understand a problem that may not enjoy any political support for a solution, influence is a difficult task. Still, the experience of communicating the research had a clear impact on the researchers.

For me, the real change that occurred in my work was the idea that we should communicate with other stakeholders and actors. Of course, I always had the idea of dissemination. But the idea that you have to establish different forms of communication to engage with different actors, that this sometimes entails building connections in new ways... this was really new for me.

The communication activities also had an influence on the research itself. According to the account of the researchers, because they were expected to communicate their findings in multiple 'policy venues', they also began to think about how power and processes in those venues related to the research. The communication activities, which brought new forms of interactive knowledge to the researchers, broadened the scope of the enquiry.

Looking forward, the researchers feel that they need to do a different kind of research to have a more profound change. To have a policy impact, they found, one would need to change how politicians view the world and the traditional manner in which they see their role - as hierarchical leaders rather than as facilitators of participatory democracy. Engineers and cartographers can make vital contributions to policy change, but in this case what was required was not so much a map but a different sense of direction from policymakers, which requires that the researchers assume a different, and perhaps unfamiliar role. 


\section{Mediators and conciliators}

Mediators and conciliators also approach research as a process of 'finding out', but they engage differently because of their interactive knowledge. These researchers serve as intermediary between disparate groups or agendas, helping to open spaces for engagement where they do not exist or are weak. This role almost always requires that the intermediary reformulate meaning between different actors, often by allowing each group to see a wider picture. In most circumstances, researchers are working between groups who want to work together. In other contexts, as conciliators, they have the task of linking groups who may be unaware of each other's existence or openly hostile to one another.

In one of the projects carried out in Bangladesh, Citizenship DRG researchers began their enquiry with surveys and interviews to determine what impact different kinds of membershipbased organisations had on the lives of their members. These methods generated instrumental and critical knowledge about the relationships and patterns between how people are mobilised and the outcomes related to those strategies and interventions. They then shared the preliminary results with the membership organisations they had studied - hoping mostly to validate the findings. Few researchers make this gesture, and the researchers would later view it as a crucial first step; the trust they established with their transparency led to increasingly sophisticated engagement that evolved over time. Eventually the researchers decided to host the Citizen's Rights Fair described in the introduction.

One of the researchers on the team wrote this reflection about the decision to host the event:

Thus during this period [the final stage of communication activities] we were no longer limiting ourselves to what we had originally outlined as our objective of the research. It was no longer the imperative of the instrumental knowledge that we started out with, but knowledge garnered from our interactions with organisations, government representatives and the donor community, that led us to the next step. From our field visits, we came to realise the sheer numbers of organisations mobilising on a variety of rights that dotted the landscape of Bangladesh. At the same time we realised that there was very little exchange and sharing between these organisations. And that in fact there were lines along which allies and adversaries positioned themselves.

At the mela, nearly 600 grassroots members performed songs, dances and dramas during the programme. Hundreds of photographs and posters on the theme of rights and citizenship were displayed at the gallery, and 57 organisations showcased their efforts to raise awareness of citizen rights at their stalls: including issues of human rights, labour rights, child rights, rights of ethnic groups, environmental rights and women's rights. The fair ended with a panel discussion of high-profile speakers on 'Fulfilling the promise of equal citizenship'.

The researchers' ability to mediate emanated from the particular kinds of knowledge generated through the research process - both instrumental and critical. The instrumental knowledge from the research - and, crucially, the way in which they had shared it - earned them the trust and respect of civil society organisations. The interactive knowledge they gained during their various communicative activities allowed them to understand those otherwise invisible lines between 'allies and adversaries'. Critical knowledge emerged through the engagement and communication elements of their work. And these forms of knowledge, in conjunction, can at times give researchers a special ability to help divided parties to see one another's perspectives.

\section{Critical friends and advocates}

Critical friends and advocates are set apart by their use of critical knowledge. These researchers have a view about how something should be. Unlike engineers, their objective is not only to convince others of how something should be done, but why - to influence people's values and beliefs. Critical friends/advocates take a normative view of research as contributing to a particular agenda. On the inside they are like a friend who dispenses advice that may not be comfortable, but that is welcomed and considered. On the outside, they must assume the role of advocate, pushing to change decisionmakers who are often dismissive or hostile to their viewpoint.

One research project in India carried out by the Society for Participatory Research in Asia 
(PRIA) examined Project Shakti, an initiative of Hindustan Unilever Limited (HUL) that was intended to promote the income-generating capabilities of underprivileged rural women by integrating them as local retailers of cosmetics and other goods. Initiated in 2001, it envisioned the creation of 100,000 Shakti entrepreneurs covering half a million villages, and touching the lives of 600 million rural people by the year 2010 .

The qualitative fieldwork for the project was undertaken in the two districts where Project Shakti was first piloted before being scaled up to seven other states. The key project stakeholders were all involved in the research. Open-ended questionnaires were administered by the local retailers themselves.

The knowledge produced was instrumental and critical. They found that the Shakti programme was successful at increasing the incomes of participating women. Despite being a part of the global economic chain, however, these women continue to view their identity locally, but in a slightly different image, that of 'hygiene amma', bringing the message of cleanliness, aspirations of the modern and popular notions of feminine beauty to villages. This different image is not without costs to most of the Shakti Amma, caused by the many problems in the actual running of dealerships. To some extent Project Shakti has undermined existing collective approaches and collective forms of self-organisation as counterhegemonic alternatives. Many self-help groups have lost their strong leaders to Project Shakti. Now occupied with meeting their sales targets, many Shakti Amma are no longer active in local politics, or less inclined to deal with larger social issues. The researchers also made their discomfort known about the way that Unilever used the social capital of these women to persuade other women to spend their money on 'beauty creams' - diverting household resources that might otherwise be spent, for example, on something like education for them or their children.

HUL reacted strongly to the findings; the company's executives did not feel that PRIA had the right to scrutinise its project and demanded that PRIA desist with the research. Being a critical friend requires a trusting relationship. PRIA contemplated an advocacy approach where going public with the findings might embarrass the company into changing.
PRIA, however, was uncomfortable with this. In fact, PRIA is an important mediator in India; the organisation's strategy to promote change relies on its ability to convene many different kinds of actors, including from the private sector. So PRIA instead approached the parent company in the UK. There, PRIA found a more responsive set of executives and they continued the discussions with them.

The framework here points to how the critical knowledge acquired by PRIA researchers threatened to push PRIA researchers from a position of critical friend to advocate. Assuming a more activist stance, however, was incompatible with PRIA's own way of working. The tension was finally resolved when PRIA researchers found a way to restore the relationship of critical friend with the parent company.

\section{Catalysts and leaders}

Catalysts and leaders pursue research as either co-construction or as action. By using these participatory and action-research methodologies, they try to initiate or sustain actions that would not happen otherwise, which in the context of research communication usually means helping a marginalised group to take their own communicative action. Catalysts and leaders are, in a sense, always on the inside, if you consider that the trust and bonds they share with the researched are essential for their success. However, taking a leadership role, in our experience, can mean that the researchers are more willing to persuade, to encourage, to inspire, and sometimes to offend. Leadership often encompasses a full range of roles, with the researcher required at times to engineer solutions, mediate between parties, criticise and facilitate.

A good example of the catalyst involves Acção para o Desenvolvimento Rural e Ambiente (ADRA), a non-governmental organisation (NGO) partner of the Citizenship DRC.

In an initial stage, the researchers from ADRA used standard qualitative methodologies to investigate whether the Núcleo Representativo das Associações do Dombe Grande, a federation of 15 local associations that emerged in the 1990s in the commune of Dombe Grande, has empowered ordinary citizens, and how this might 


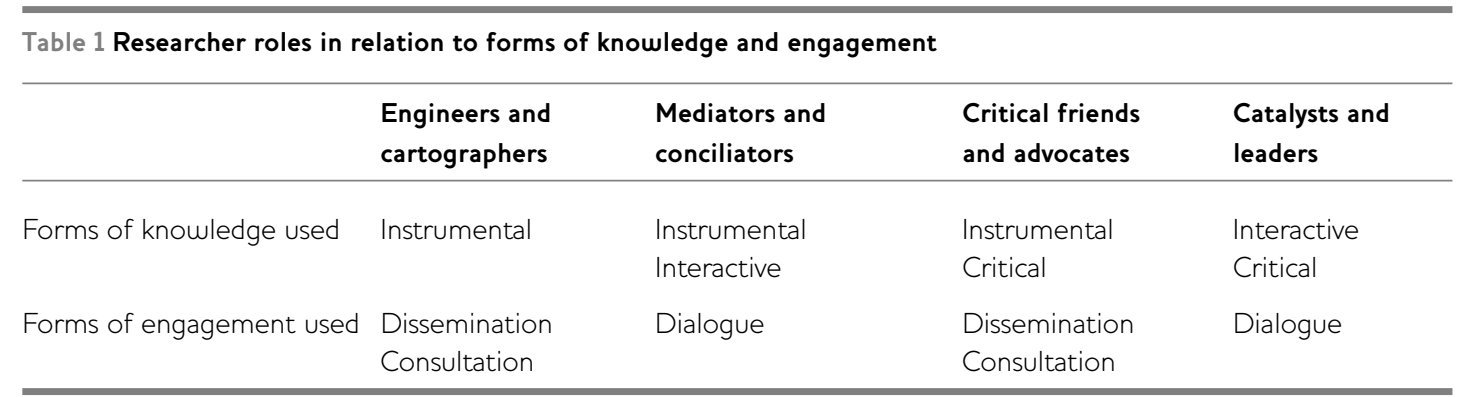

be contributing to the country's democratisation process. This research found that the operation of the Councils for Social Consultation and Dialogue (CACS) differs from one municipality to another and the administrator's profile is a key element to boost participation in this space. The CACS are considered by those interviewed to be a 'breakthrough in terms of accountability', in spite of their shortcomings.

It is worth noting, however, that ADRA shared a history with these actors; it had directly supported their formation. Because of this history, ADRA researchers were later comfortable leading a participatory video project with members of the associations on the issues raised by the research. The participatory video was linked also to a series of dialogues with local government representatives, civil society groups and academics. The combination of the research, the participatory video and the dialogues generated interactive and critical knowledge. Association leaders gained an interactive understanding of other political actors, whilst at the same time developing a new normative position of their role in democracy.

... the research opened spaces for the associations to reflect deeply about their history and role in the local context and also in the wider context of the country. Secondly, the research allowed the development of capacities within the groups, influenced the empowerment of leaders who began to act in the context of Dombe Grande. Third, through the communication activities, the research opened space outside Dombe Grande for the leaders of the associations to communicate their experience and research results themselves.

The research did not lead to any significant changes in the way that the CACS are managed, but it did spark new actions within the associations, which are still working for greater voice and recognition in local government. This new action was partly a matter of gaining new skills, but mostly a result of how the co-construction process gave local leaders a new sense of purpose - a form of critical knowledge.

Like the other research projects described, the work in Dombe Grande evolved over time, though perhaps with less tension. The switch to participatory video as a research methodology brought in new forms of knowledge and opened the way for the researchers to assume a role as catalyst. Because of the organisation's own history (and the profiles of the researchers), this role was comfortable. This highlights one of the advantages to methodological flexibility, which allowed the researchers to find suitable matches between their methodologies and strategies for influence.

\section{Understanding the importance of researcher roles to influence}

The preceding sections have explored a series of roles that researchers play in processes of communication that emerged through a collaborative global research network. These roles are often based on different assumptions about the nature of research and rely on the particular forms of knowledge generated through distinct research processes. This framework offers a way for researchers to think more critically about how they approach change. It does not offer a means of assessing impact, but rather opens the field of inquiry about research communication to include the position and role of the researcher in relation to their assumptions about research, and the forms of knowledge this generates.

This framework can be useful in practice because it can help researchers and those working with researchers to plan communication strategies that are suited to their particular roles and the forms of knowledge that their approach to research will be likely to generate. It can also 
provide an approach to understanding and assessing the influence of their work based on the types of outcomes that can be expected. For example, instrumental knowledge generated through research as finding out could be used by a 'cartographer/engineer' researcher in particular ways to lead to improvements in policy, as described in the case of Vale do Ribeira in Brazil. The interactive and critical forms of knowledge that emerge from research as coconstruction can lead to changes in how researchers as mediators approach change, as in the case of research with Unilever in India.

\section{Notes}

* Nicholas Benequista was the Communication Officer for the Citizenship DRG from 2008 to 2010, and previously worked as a Research Assistant and Intern to the project. Joanna Wheeler was the Research Manager of the Citizenship DRG from 2003 to 2010 and a researcher in one of the thematic areas of the Citizenship DRG.

\section{References}

Cooke, B.and Kothari, U. (2001) 'The Case for Participation as Tyranny', in Participation: The New Tyranny?, London: Zed Books: 1-15

Court, J. and Young, J. (2003) Bridging Research and Policy: Insights from 50 Case Studies, ODI Working Paper 213, London: Overseas Development Institute

Eyben, R. (2009) 'Hovering on the Threshold: Challenges and Opportunities for Critical and Reflexive Ethnographic Research in Support of International Aid Practice', Ethnographic Practice and Public Aid: Methods and Meanings in Development Cooperation, Uppsala: University of Uppsala: 71-98

Habermas, J. (1984a) The Theory of Communicative Action, Vol. 1, London: Heinemann Education

Habermas, J. (1984b) The Theory of Communicative Action, Vol. 2, London: Heinemann Education

Jones, H. (2009) Policy-making as Discourse: A Review of Recent Knowledge-to-policy Literature, Joint IKM Emergent-ODI Overseas Development Institute Working Paper, London Maxwell, S. (2003) 4x Policy Entrepreneurs, London: Overseas Development Institute, www.odi.org.uk/rapid/tools/toolkits/policy_ impact/Policy_entrepreneurs.html (accessed 9 July 2012)

Nutley, S.; Walter, I. and Davies, H. (2002) From Knowing to Doing: A Framework for Understanding
The analysis of the case studies shows that the research results alone may have been useful to particular policymakers (within NGOs, local and national governments, etc.). However, the more important finding is that the process of communication emerging through the research also underscored how using different forms of knowledge for engagement can also alter the social relations within which that knowledge is considered. The shifts in perspectives of the researchers themselves, especially in relation to the various networks in which they work, is a very significant and often overlooked area of change.

1 Complete details on this project can be found at www.drc-citizenship.org (accessed 29 June 2012).

2 A more elaborate framework for understanding forms of engagement might, for example, draw upon Jurgen Habermas' theory of communicative action, but given the space constraints of this article, we have used a more narrow categorisation.

the Evidence-into-Practice Agenda, RURU Discussion Paper 1, St Andrews: Research Unit for Research Utilisation, University of St Andrews

Park, P. (2001) 'Knowledge and Participatory Research', in P. Reason and H. Bradbury (eds), Handbook of Action Research: Participative Inquiry and Practice, London: Sage

Reason, P. and Bradbury, H. (eds) (2008) Handbook of Action Research, London: Sage Reimers, F. and McGinn, N. (1997) Informed Dialogue: Using Research to Shape Education Policy Around the World, London: Praeger Publishing

Walter, I.; Nutley, S.; Davies, H. and Practice, E.N. (2003) Developing a Taxonomy of Interventions used to Increase the Impacts of Research, St Andrews: Research Unit for Research Utilisation, University of St Andrews

Weiss, C. (1991) 'Policy Research as Advocacy: Pro and Con', Knowledge and Policy 4.1/2: 37-56

Weiss, C. (1977) 'Research for Policy's Sake: The Enlightenment Function of Social Science Research', Policy Analysis 3.4: 531-45

Wheeler, J. (2007) Creating Spaces for Engagement: Understanding Research and Social Change, Brighton: The Development Research Centre on Citizenship, Participation and Accountability 